\title{
LAS NORMAS COMPLEMENTARIAS Y SUBSIDIARIAS DEL PLANEAMIENTO SOLO SON DE APLICACION SI NO EXISTE PLAN DE URBANISMO O PARA LLENAR LAGUNAS DEL MISMO
}

$711: 35$

por

\section{Nemesio Rodríguez Moro}

Así viene a consignarlo la sentencia de 28 de noviembre de 1976 (Ar. 5950), aplicando las disposiciones contenidas en los artículos 57 y siguientes de la Ley del Suelo de 12 de mayo de 1956, que en este particular no ha sufrido variación por el nuevo texto de la Ley del Suelo de 9 de abril de 1976, que trata de este asunto en los artículos 70 al 75.

En la sentencia antes mencionada se sienta el principio fundamental que estas normas son disposiciones de carácter general cuya finalidad es suplir la falta o insuficiencia de los planes de ordenación; y si bien están pensadas para los casos en que falta el Plan, es indudable que serán de aplicación cuando, aun existiendo Plan general, falte Plan parcial, e igualmente para aquellos casos en que se produzca una laguna en las previsiones del Plan, que podrá ser llenada con las normas complementarias y subsidiarias del planeamiento. Por eso dispone el número 2 del artículo 71 del texto ahora vigente, que tales normas se aplicarán igualmente para regular aspectos no previstos en el Plan de ordenación. 
Pero lo que resulta indudable, y ésta es la tesis de la sentencia referenciada, es que si existe debidamente aprobado un Plan, no pueden aplicarse disposiciones de las normas complementarias y subsidiarias en cuanto se hallen en oposición con las disposiciones del Plan en vigor. Por ello, las Corporaciones locales deben tener muy en cuenta, cuando se trate de otorgar licencias de obras, que tales normas complementarias y subsidiarias no pueden ser tenidas en cuenta cuando contradicen las disposiciones de un Plan de ordenación urbana debidamente aprobado, debiendo ser aplicadas solamente las disposiciones del Plan. Y con independencia de que los particulares afectados puedan ejercitar las oportunas acciones administrativas y judiciales en defensa de sus particulares intereses, son los Ayuntamientos, y en su defecto los organismos encargados de vigilar el cumplimiento de las disposiciones que amparan el interés general de la comunidad, los que deben preocuparse de que al socaire de tales normas complementarias no se distorsione la ejecución del ordenamiento urbanístico.

La sentencia en cuestión consigna los siguientes considerandos:

Considerandos de la sentencia apelada que se aceptan:

Considerando: Que el problema que se debate en el presente juicio es si son aplicables o no las Normas de Ordenación Complementarias y Subsidiarias del Planeamiento aprobadas para los Municipios de la Provincia de Pontevedra, y publicadas en los Boletines Oficiales números 17, 18, 21 y 22 de enero de 1974, según se indica por el Ayuntamiento recurrido en el expediente administrativo, y por la representación del mismo en la contestación a la demanda; no obstante, el accionante indica que estas normas no pueden regir, por cuanto existe aprobado un Proyecto de Ensanche en esa Villa desde el 16 de enero de 1946 y un Plan Parcial de Ordenación Urbana desde el día 9 de julio de 1969, comprendido entre las carreteras de Monforte y Lugo, donde está situada la finca del recurrente, Plan aprobado también por la Comisión Provincial de Arquitectura y Urbanismo de Pontevedra en 17 de septiembre del mismo año, según certificación del señor Secretario de aquel Ayuntamiento; evidentemente, el artículo 57 de la Ley del Suelo preceptúa que «1. El Ministro de la Gobernación podrá dictar, a propuesta del Consejo Nacional de Urbanismo, normas complementarias y subsidiarias del planeamiento. 2. Las Comisiones provinciales de Urbanismo podrán también proponer normas de igual carácter para la Provincia o lugares determinados. 3. Dichas normas se desarrollarán, en todo caso, dentro de los límites que señala esta Ley para los planes de urbanismo», o sea, que para suplir la falta de 
los planes de ordenación municipales, el artículo $8 .^{\circ}$ de la Ley del Suelo, al regular los planes provinciales, dispone que los mismos comprenderán (ap. 3) «normas urbanísticas... para la edificación en todos los terrenos respecto de los cuales no hubiere planeamiento aprobado" $y$, para cuando no existe Plan ni ninguna norma en el Plan provincial, o para cuando existiendo son insuficientes, están las normas que prevén los artículos 57 y 58; las normas complementarias y subsidiarias de planeamiento son disposiciones generales cuya finalidad es suplir la falta o insuficiencia de los planes de ordenación (artículo 58 de la Ley del Suelo); participarán de la naturaleza jurídica de los planes, por lo que son disposiciones de carácter general, si bien sujetas al régimen de impugnación de los actos administrativos $\mathrm{y}$, al participar de la naturaleza de los planes, están sujetas a los límites que la Ley señala para éstos (art. 57, párrafo 3, Ley del Suelo), si bien el régimen jurídico de la elaboración es distinto; estas normas subsidiarias podrán ser, por el ámbitc: de aplicación: Estatales (párrafo 1 del artículo 57); Provinciales (art. 52, párrafo 2) y, para lugares determinados, que podrán referirse a una Comarca, a un Municipio o incluso a parte del término de un Municipio; y según el artículo 57, párrafo 3, estas normas "se desarrollarán, en todo caso, dentro de los límites que exija esta Ley para los planes de urbanismo", lo que supone la subordinación a las normas de superior jerarquía (Leyes y Decretos), no poder exceder en su contenido del que prevé la propia Ley del Suelo para los planes, según los casos (artículos 7, 8, 9, 10 y 13 a 20), y han de limitarse a suplir la falta o deficiencia del Plan, y una vez publicadas, producirán los mismos efectos que los planes en el territorio a que se refieran, de conformidad a lo dispuesto en el artículo 58, Ley del Suelo; y el artículo 58 de la misma Ley establece: «1. En las poblaciones donde no existiere Plan de ordenación urbana debidamente aprobado regirán las normas promulgadas con arreglo al artículo anterior. 2. Las propias normas se aplicarán para regular aspectos no previstos en el Plan de ordenación", o sea, que del propio precepto se desprende que estas normas serán de aplicación cuando en el término municipal falte el Plan general de ordenación urbana; las normas subsidiarias del artículo 57 están pensadas especialmente para la falta de este Plan, pero nada impide que también se dicten para aquellos casos en que, existiendo Plan general, falte Plan parcial, regulando supuestos tipo, regirán en tanto no se apruebe definitivamente el Plan y se cumpla el requisito de publicidad para que entre en vigor, $y$, dándose los requisitos señalados, regirán las normas $\mathrm{y}$, a tenor de lo que en ellas se disponga, se producirán los mismos efectos que con el Plan y para que éstas rijan en el territorio o sector que tenga Plan de ordenación, será necesario que se dé un aspecto de la ordenación no previsto en el Plan; las normas sólo regirán en tanto exista una laguna en la ordenación del Plan, pero en el caso de autos existe un Plan Parcial de Ordenación en el Ayuntamiento de Lalín, como se indicó con antelación, con anterioridad a la publicación de las Normas Complementarias y Subsidiarias de Planeamiento para los Municipios 
de la Provincia de Pontevedra, pero la Villa de Lalín contaba ya con un Proyecto de Ensanche en el expresado Plan de Ordenación, y teniendo en cuenta lo señalado por los artículos 57 y 58 de la Ley del Suelo antes transcritos, si no existiere Plan de Ordenación en aquel Municipio, regirán las Normas anteriormente citadas, pero existiendo éste y regulando la materia urbanística objeto de debate, las Normas aludidas carecen de eficacia, salvo que en el Plan de Ordenación comentado no se regulase algún aspecto de la materia urbanística, entonces serían aplicables dichas Normas solamente en los supuestos no regulados en el indicado Plan, pero según se desprende del expediente administrativo y en las presentes actuaciones, desde la fecha de su aprobación, el Ayuntamiento de Lalín se atiene a lo normado en el mismo para la concesión de licencias de edificación.

Considerando: Que en vista de lo indicado con antelación, se puede llegar a las siguientes conclusiones: 1.a Que el Plan o Proyecto de Ensanche de la Villa de Lalín fue aprobado por el Ayuntamiento en Pleno, en sesión celebrada el 16 de enero de 1946, y por los Organismos provinciales correspondientes, el día 15 de abril del mismo año; 2.a Que en plena vigencia de la Ley del Suelo, el 9 de julio de 1969 el Ayuntamiento aprobó el Plan Parcial de Ordenación Urbana de la zona comprendida entre las carreteras de Monforte y Lugo, que asimismo fue aprobado por la Comisión Provincial de Arquitectura y Urbanismo de Pontevedra en sesión celebrada en 17 de septiembre del mismo año; 3. ${ }^{a}$ Que con arreglo a las previsiones contenidas en el Plan o Proyecto de Ensanche de la Villa, en cuyo perímetro se halla situada la finca del recurrente, se han llevado a cabo las obras de urbanización de varias vías públicas, entre las que se encuentran las calles Arenal, General Franco, Matemático Rodríguez y la calle del Puente; 4.a Que en el perímetro delimitado por dicho Plan o Proyecto, con arreglo a las condiciones preestablecidas en las Ordenanzas Municipales de Construcción y Vivienda, el Ayuntamiento vino concediendo licencias de edificación, hasta la publicación de las Normas Complementarias y Subsidiarias del Planeamiento para los Municipios de la Provincia de Pontevedra, en enero de 1974; y, con arreglo al artículo 12 de la Ley del Suelo, «los planes y proyectos municipales de ordenación y urbanización que no abarcaren la totalidad del término se calificarán de reforma interior o de extensión, según los sectores a que afectaren». Serán planes o proyectos de reforma interior los concernientes al casco urbano y encaminados a sanear barrios insalubres, y resolver problemas de circulación o de estética, mejorar los servicios públicos o realizar otros fines semejantes. Serán planes y proyectos de extensión los relativos a superficies de suelo exteriores al casco urbano. El casco comprenderá los sectores urbanizados a medida que la construcción ocupe dos terceras partes de la superficie edificable en cada polígono; y la exigibilidad de las previsiones contenidas en los planes o proyectos de ensanche anteriores y durante la vigencia de la Ley del Suelo, y en las ordenanzas de edificación municipales, se califican por la doc- 
trina jurisprudencial interpretando la disposición transitoria novena de la Ley del Suelo, como constitutivas de planes de ordenación urbana, sentencias de 13 de febrero de 1960, 28 de mayo de 1963, 28 de febrero de 1967; existiendo para esta zona Plan de Ordenación o Planeamientos urbanísticos debidamente aprobados, no son de aplicación al caso de autos las Normas Complementarias y Subsidiarias de Planeamiento, invocadas por la Administración.

\section{Considerandos del Tribunal Supremo:}

Considerando: Que abundando en la tesis sostenida en los precedentes considerandos de la sentencia que se apela, y habida cuenta de que los argumentos en que el Abogado del Estado se basa para fundamentar en Derecho su apelación, no difieren de los invocados en la primera instancia, esta Sala estima: 1. Que no obstante su denominación de Proyecto de ensanche en la terminología del artículo 130 de la Ley de Régimen local y de la vieja Ley de 26 de julio de 1892, o indistintamente de Proyectos o Planes de extensión según expresión del artículo 12 de la Ley del Suelo de 12 de mayo de 1956, ambas Ordenaciones urbanísticas son verdaderos planes de ordenación urbana territorial, si bien de ámbito limitado, que, como los planes parciales, gozan de autonomía cuando no preexiste un Plan General a cuyas previsiones deberán supeditarse. 2. ${ }^{\circ}$ Que, en consecuencia, no debe incurrirse en el error que por su sola denominación de Proyectos -contenida en el mencionado artículo de la Ley de Régimen local, anterior y menos técnica y precisa que la Ley del Suelo- pueda ser identificado o confundido con los Proyectos de Urbanización regulados en esta última Ley como escalafón ejecutivo del programa ordenador que los Planes propiamente dichos contienen. Por el contrario, constituyen con carácter general en la técnica de la antigua legislación y con carácter excepcional en los casos comprendidos en el artículo 12 , párrafo $2 .^{\circ}$, de la vigente Ley del Suelo, verdaderos Planes de Ordenación urbanística. 3. Como consecuencia, toda alusión legal a la existencia o inexistencia de planes de ordenación urbana, y por tanto la que contiene el artículo 58 de la Ley del Suelo al contemplar los supuestos de aplicación de las Normas Subsidiarias o Complementarias de Planeamiento, debe entenderse referida no sólo la ordenación general urbanística (planes generales), sino también la de carácter parcial propia de los planes de este nombre, y la especial y de ámbito restringido que integran los planes o proyectos de reforma interior o extensión del artículo 12 de la Ley del Suelo o los proyectos de ensanche de la legislación anterior (artículo 130 de la Ley de Régimen local en relación con la de 26 de julio de 1892).

Considerando: Que en virtud de cuanto queda expuesto, la existencia en el Ayuntamiento de Lalín (Pontevedra) por una parte de un Proyecto de Ensanche con sus Ordenanzas de Construcción y Vivienda 
aprobadas con arreglo a sus previsiones, y por otro de un Plan parcial, excluye la posibilidad de aplicar en el ámbito parcial y limitado en que aquellas ordenaciones debidamente aprobadas tienen vigencia, las previsiones de las Normas Subsidiarias para la Provincia de Pontevedra. No contradice válidamente esta conclusión la inexistencia de un Plan general municipal, por cuanto la finalidad de la norma subsidiaria es el vacío planificador allí donde exista y no hay tal vacío y por tanto no es aplicable el artículo 58 de la Ley del Suelo en las zonas del $\mathrm{Mu}$ nicipio de Lalín ordenadas por el Plan parcial y el Plan o Proyecto de ensanche tantas veces aludido; donde falta ordenación urbanística es en el resto de la población. De lo contrario se desconocería el carácter autónomo que la doctrina más general y la jurisprudencia (ejemplos: sentencias de 13 de noviembre de 1975,8 de noviembre y 26 de junio de 1974, 2 de octubre de 1972) vienen a reconocer a los planes parciales admitiendo su aprobación y vigencia sin la preexistencia de Plan

1 General, en razón a la necesidad de agilizar el desarrollo urbanístico, y cuanto se dice del Plan parcial, conviene también, y con mayor motivo dada su especialidad, a los planes o proyectos de reforma interior o ensanche. Por todo ello no puede prosperar la tesis mantenida en la apelación, procediendo la confirmación de la sentencia. 